\title{
Experimental characterization of heavy halogens behavior in alkaline magmas
}

\author{
CARMELA FEDERICA FARANDA, PHD, GAËLLE \\ PROUTEAU, BRUNO SCAILLET AND JOAN ANDÚJAR \\ Univ. Orléans, CNRS, BRGM, ISTO \\ Presenting Author: carmela-federica.faranda@etu.univ-orleans.fr
}

Halogens are minor volatile species emitted during volcanic eruptions, whose injection into the atmosphere contributes to the diminution of the stratospheric ozone layer and causes major climatic impacts. However, the lack of detailed understanding concerning halogens behavior in magmas - especially bromine and iodine - and their degassing during magma ascent, prevents a full assessment of halogen cycling in the Earth's system. Previous studies on iron-free synthetic systems have shown that the partitioning of $\mathrm{Cl}, \mathrm{Br}$ and I between fluids and silicate melts increasingly favors the former as the ionic radii of the halogenide ions increases [1]. These results suggest that bromine and iodine fluxes to the atmosphere are probably underestimated. To evaluate this phenomenon, additional experimental constraints on $\mathrm{Br}$ and $\mathrm{I}$ behavior in natural magmas are urgently needed. In this study, the Br partitioning between fluids and natural silicate melts has been investigated experimentally as a function of melt composition, pressure, temperature and oxygen fugacity. Composition investigated and corresponding geodynamic settings are representative of alkaline/hyperalkaline magmatic systems worldwide. Experiments were performed in internally heated pressure vessels (IHPV) under controlled oxygen fugacity and allowing drop quench. Bromine abundances were determined by $\mu$-XRF, LA-ICP-MS or nanoSIMS, while fluid composition was estimated by mass balance calculations. Our results confirm the preference of bromine for the fluid phase, whatever the experimental conditions investigated, being in agreement with previous studies on metaluminous compositions [2], $D_{B r}{ }^{f / m}$ increasing with melt silica content. Due to its very low concentration in magmas, iodine behavior remains particularly poorly known. To address this issue, we have carried out HP-HT solubility experiments to synthesize a series of reference glasses, in order to test several sensitive analytical techniques for iodine quantification, such as LA-ICP-MS, nanoSIMS or neutron irradiation noble gas mass spectrometric technique. Data acquired in this study will enrich a still fragmentary knowledge of deep halogens geochemistry and therefore constitute part of the essential basis to develop the first physically-based quantitative framework for volcanic heavy halogen emissions.

[1] Bureau et al., (2000), Earth And Planetary Science Letters 183, 51-60.

[2] Cadoux et al., (2018), Earth And Planetary Science Letters 498, 450-463. 